Disponível em http://www.anpad.org.br/rac

RAC, Curitiba, v. 14, n. 3 pp. 558-569, Mai./Jun., 2010

\title{
Afinal, Quantas Empresas tem esta Cidade?
}

\section{After All, How Many Companies are there in This Town?}

\section{Rosane Rivera Torres *}

Doutora em administração de empresas pela FEA/USP. Professora da Escola de Artes, Ciências e Humanidades da USP, São Paulo/SP, Brasil.

Andréa Leite Rodrigues Doutora em administração de empresas pela FGV-EAESP. Professora da FGV-EAESP, São Paulo/SP, Brasil. 


\section{INTRODUÇÃO}

Sentadas na sala dos professores, Helena e Sofia olhavam com desânimo os resultados do trabalho da última semana. Ambas, naquela época, docentes do Curso de Administração de Empresas do Centro de Ciências Sociais e Aplicadas [CCSA] da Universidade Presbiteriana Mackenzie, tanto no câmpus na cidade de São Paulo, quanto no câmpus de Barueri, município situado na grande São Paulo. Naquele momento, conversavam mais uma vez sobre as dificuldades em obter dados primários para o projeto de pesquisa que desenvolviam no Câmpus de Tamboré, em Barueri. Um ano antes, quando propuseram o projeto ao Mackpesquisa ${ }^{(1)}$, não imaginavam as dificuldades que encontrariam para definir o universo de empresas no município de Barueri. Depois de tanto trabalho, as docentes ainda não conseguiam responder a questões que lhes pareciam tão simples no começo: Quantas empresas existem no município de Barueri? Quais suas características: setores de atividade, tamanho em volume de venda e em faturamento? Quantos funcionários e qual perfil de cargos e funções?

\section{O Projeto de Pesquisa}

A unidade do CCSA - Tamboré, contava aproximadamente 1000 alunos, que frequentavam dois cursos de graduação no período noturno: Administração de Empresas e Administração de Empresas com Habilitação em Comércio Exterior. Naquele ano, o câmpus passara a ter turmas para ambos os cursos também no período da manhã. Além disso, havia cerca de 150 alunos que frequentavam cursos de pós-graduação lato sensu.

Como parte do planejamento do CCSA - Tamboré, um grupo de docentes, liderados por Helena, desenvolveu um projeto de pesquisa, utilizando a prática de pesquisa-ação, com vistas a gerar informações sobre características dos ambientes interno e externo daquela unidade de ensino. Tais informações seriam a matéria prima para a geração de mudanças no currículo escolar e no projeto pedagógico dos cursos de graduação, pós-graduação e extensão, em administração de empresas, oferecidos no CCSA - Tamboré. Entende-se por projeto pedagógico um conceito amplo que se refere ao conjunto de disciplinas e a todas as outras atividades desenvolvidas, tendo em vista a formação do aluno $^{(2)}$. Como líder do projeto, Helena acreditava que mudanças no projeto pedagógico deveriam acontecer a partir de duas premissas, explicitadas abaixo.

1) Todos os atores sociais relevantes para o CCSA - Tamboré, deveriam estar envolvidos. Portanto docentes, discentes e representantes da comunidade empresarial circunvizinha deveriam participar da construção de um novo projeto pedagógico. Não bastava repetir em Tamboré o projeto pedagógico do Câmpus do Mackenzie em São Paulo. O objetivo do trabalho era consolidar um espaço de ensino e pesquisa pertinente à identidade do público daquela região.

2) Ao planejar projetos pedagógicos, deve-se começar pelas reflexões de qual o perfil do aluno que se quer formar. Tal ideia está em sintonia com as últimas diretrizes curriculares definidas pela Lei $\mathrm{n}^{\circ}$ 9.394, de 20 de dezembro de 1996, popularmente conhecida como Lei de Diretrizes e Bases da Educação Nacional ou simplesmente LDB/1996. Seguindo a ideia explícita na lei, só se poderia pensar no aluno a formar, se o contexto social e econômico de todos os atores sociais envolvidos com aquele espaço escolar fosse conhecido. Portanto o trabalho começaria por conhecer pessoas, lugares, fatos e contextos que envolviam o CCSA - Tamboré.

Com base em tais premissas, surgiu o projeto de pesquisa Conhecendo Tamboré: uma análise do ambiente que utiliza pesquisa-ação, projeto definido como proposta de investigação destinada a gerar conhecimento sobre empresas da circunvizinhança, comunidade, docentes e discentes do CCSA - Tamboré. Tal projeto recebeu fundos de apoio do Mackpesquisa e foi definido, originalmente, em duas fases. 
Fase 1. Levantamento de características de empresas localizadas na circunvizinhança da unidade do CCSA - Tamboré. Para fins operacionais, denominou-se como ambiente externo o conjunto de organizações empresariais localizadas nos municípios de Barueri e adjacências. Dados quantitativos seriam levantados por meio de questionário estruturado, disponibilizado eletronicamente para gestores que trabalhassem em empresas da região. Levantar-se-ia um rol de informações junto a organizações, potenciais parceiras da unidade, considerando os imensos parques industriais localizados nos municípios de Barueri e vizinhos. A ideia era estabelecer estratégias de relacionamento, a partir de programas de parceria para incentivo do intercâmbio entre empresas e universidade. Ao final desta fase, os dados levantados deveriam ser suficientes para responder às seguintes questões:

1) Quais as empresas localizadas no município de Barueri?

2) Quais os setores da indústria, números gerais do faturamento e quantidade de funcionários?

3) As empresas identificadas na questão a oferecem incentivos à realização de cursos de graduação e pós-graduação a seus funcionários? Em caso positivo, quais? Quais as características do público potencial de alunado ligado ao quadro de funcionários destas organizações?

Que sabem os profissionais de gestão acerca das pessoas presentes nestas organizações sobre o Mackenzie? E sobre o Mackenzie Tamboré?

Fase 2. Dedicada ao conhecimento da opinião de alunos e docentes do CCSA - Tamboré, quanto ao currículo e projeto pedagógico da unidade. Entrevistas em profundidade e focus groups, técnicas apropriadas à coleta de dados para pesquisas qualitativas, viabilizariam o conhecimento mais profundo das impressões desses atores sociais.

O produto final do trabalho realizado nas duas fases seria um arcabouço de conhecimento para o desenvolvimento de mudanças no currículo e no projeto pedagógico dos cursos de graduação e pósgraduação em Administração de Empresas do CCSA - Tamboré.

\section{O TRABALHO DAS PESQUISADORAS}

No momento em que Helena e Sofia conversavam na sala dos professores, a realização da Fase 1 excedia em muito o tempo que fora planejado no cronograma do projeto, e ainda não havia resultados confiáveis. Sofia, professora-doutora, com formação em métodos quantitativos de pesquisa, docente em disciplinas de estatística e pesquisa em marketing, assombrava-se com a dificuldade em definir o próprio universo! Sendo Barueri um município que oferece benefícios fiscais a empresas que lá se estabelecem, ao tentar definir quantas empresas estão localizadas no município, as pesquisadoras depararam-se com as chamadas empresas de papel, ou seja, apesar dos registros de uma empresa constarem formalmente da relação das que estão localizadas no município, não raro suas operações e atividades acontecem em outro lugar. Considerando que o objetivo do projeto de pesquisa era gerar conhecimento sobre empresas vizinhas, com o fim de realizar parcerias, as empresas de papel não ofereceriam nenhuma contribuição importante. Como definir, então, quantas empresas estavam, de fato, em Barueri?

Helena e Sofia concluíram que, ao iniciar o projeto de pesquisa, não tinham a menor ideia da dificuldade que enfrentariam para localizar empresas em Barueri, pois, transcorridos oito meses de trabalho, ainda era alto o nível de dificuldade para concluir pelo menos a Fase 1. Vejamos como o trabalho aconteceu.

Inicialmente, pensaram que o contato com a Prefeitura seria suficiente, porquanto esta já organizara um sitio eletrônico (website), que continha um banco de dados com todas as empresas registradas no município. Ao acessar www.barueri.sp.gov.br é possível obter facilmente uma lista com a relação das empresas cadastradas no município, apresentadas em banco de dados com aproximadamente 19.000 
empresas, classificadas em 46 ramos ou setores econômicos. A partir disto, as professoras pensaram em definir uma amostra probabilística estratificada. No entanto duas questões inviabilizaram esta opção durante o trabalho de pesquisa.

Primeiramente, o banco de dados englobava todo tipo de empresa, o que gerava uma imensa variedade de organizações, em tamanho e setor de atuação. Por conseguinte, havia registros de empresas que variavam de ambulantes a filiais de empresas multinacionais de grande porte, como é o caso da americana Hewlett Packard [HP]. Concluiu-se que não se poderia considerar o total de registros do banco como equivalente ao universo de organizações para fins de definição da amostra, pois o objetivo do projeto de pesquisa requeria entender as relações entre o ambiente circunvizinho e o próprio CCSA - Tamboré. Consequentemente, o universo de organizações considerado deveria ser tal que contivesse apenas organizações passíveis de estabelecer relações com o Mackenzie Tamboré. Este não seria o caso, por exemplo, de farmácias, açougues ou cabeleireiros, para citar apenas alguns. Fezse, então, um primeiro trabalho de seleção, restando 2973 empresas consideradas como potenciais parceiros.

Em segundo lugar, empresas de papel não interessavam, por definição, pois não representariam potenciais parceiros. Em outras palavras, dos 2973 registros resultantes da (ampla) eliminação de microempresas do banco de dados, ainda deveriam ser desconsiderados todos aqueles relacionados a organizações cujas fábricas e escritórios não estavam localizadas no município. Aqui residiu a maior de todas as dificuldades do trabalho de pesquisa. Como saber se determinada razão social registrada em Barueri representava ou não uma organização com atividade efetivamente desempenhada no município?

Para lidar com estes obstáculos, as professoras precisaram de novos métodos para seleção. Começaram tentando gerar listas telefônicas e realizar contatos. O procedimento mostrou-se moroso e improdutivo, como se poderia esperar. O levantamento dos números de telefones já implicava listas incorretas, incompletas ou que resultavam em contatos sem qualidade. Não raro, um número de telefone correto estabelecia o contato com um escritório de contabilidade, contratado pela empresa de papel para representá-la em Barueri.

As professoras, então, começaram a realizar levantamentos com os alunos, tentando gerar listas com registros de local, endereço e telefone de contato profissional, com o objetivo de arregimentar nomes de empresas (de verdade!) no município. Esse procedimento resultou bem mais produtivo; afinal os próprios alunos começaram a promover apoio ao projeto de pesquisa dentro das empresas em que trabalhavam ou estagiavam. Apesar da boa vontade e empenho de todos, o número de empresas que aderiram por esta via de contato foi pequeno, em torno de 20 nomes apenas.

Helena e Sofia continuavam, portanto, diante de uma tremenda dificuldade em realizar a Fase $\mathbf{1}$ da pesquisa. Como estabelecer o universo e o plano amostral de empresas que efetivamente estivessem localizadas em Barueri? Como localizá-las? Qual seu perfil de atividade? Passados oito meses de trabalho, estas perguntas ainda continuavam sem resposta e as pesquisadoras já cogitavam a hipótese de deixar de lado a ideia de amostragem probabilística e pensavam fazer levantamentos por critérios de acessibilidade às empresas. Outro problema: se assim procedessem, não seria possível avaliar as reais possibilidades do CCSA - Tamboré, em termos de parcerias com empresas na região. Diante deste cenário, as pesquisadoras se perguntavam: quais seriam os impactos da mudança de estratégia de coleta de dados para a elaboração do novo projeto pedagógico? 


\title{
NOTAS DE ENSINO
}

\section{Resumo do Caso}

Barueri é um municipio da Grande São Paulo, localizado a oeste da capital. A cidade oferece alíquotas diferenciadas para impostos a empresas que ali se instalam, tornando-se importante polo de atração industrial. Em virtude da oferta de tais benefícios, o município ficou repleto de empresas de papel, ou seja, empresas se estabelecem formalmente na cidade, mas não desenvolvem ali sua operação. Tal fato torna difícil a tarefa de identificar organizações cujas operações aconteçam efetivamente no município. O contato telefonico com uma empresa com sede em Barueri resulta, frequentemente, em tratar com um escritório de contabilidade que a representa, uma vez que a operação está em outros lugares. A Universidade Presbiteriana Mackenzie pretendeu produzir um trabalho de aproximação com empresas da região, em face dos planos de desenvolvimento estabelecidos para o câmpus Tamboré, localizado em Barueri. Desta feita, era imprescindível definir universo e plano amostral com empresas cujas operações ocorressem na circunvizinhança, com vistas a estabelecer programas de parcerias. Deu-se, então, o desafio de encontrar quais organizações estavam efetivamente no municipio, uma vez que as empresas de papel não interessavam para os propósitos de desenvolvimento do campus. Como encontrá-las?

Palavras chave: método de pesquisa; pesquisa de campo; dados primários e plano amostral.

\begin{abstract}
Barueri is a small country town, located to the west of São Paulo City. The town offers tax exemptions to companies that set up business there, becoming an important industrial area and cluster. As a consequence, Barueri has filled up with paper companies, that is, companies that exist only for formal burocratic purposes, but which do not really conduct their operations there. The task of identifying which companies really conduct their operations in the town is difficult. Frequently, a contact with a company with headquarters in Barueri results in dealing with a professional accounting office professional which represents it, with the organization effectively being located outside the town. The Presbyterian Mackenzie University intended to establish relationships with companies of the region, considering the plans of development for the Tamboré Campus, located in Barueri. Consequently, it was essential to define a universe and a sample of companies whose operations occurred in the surrounding area of the Campus in order to establish partnership programs. It was therefore faced with the challenge of finding which companies were effectively located in Barueri, since paper companies have no interest in the development of the campus. How to find them?
\end{abstract}

Key words: research method; field research; primiry data; sample plan.

\section{Objetivos educacionais do Caso}

a) Proporcionar uma experiência vicariante para desenvolvimento de competências no levantamento de dados primários confiáveis e pertinentes.

b) Possibilitar aos alunos enfrentar uma situação real na qual dados disponíveis publicamente não são adequados para os objetivos de um estudo. Há, portanto, necessidade de desenvolver estratégia de coleta alternativa.

\section{Utilização Recomendada}

O presente caso destina-se a disciplinas que tratem diretamente de questões básicas de um desenho de pesquisa. É o caso, por exemplo, de Metodologia de Pesquisa, Pesquisa de Marketing, Amostragem, entre outras. Sugere-se que seja material didático de apoio para a discussão de conteúdos que requeiram definição de plano amostral, que envolve dados primários e secundários. Destina-se a 
promover debates sobre as formas eficientes e eficazes de se conduzir uma pesquisa de campo segundo a moderna teoria de planejamento e condução de procedimentos amostrais.

\section{QUESTÕES PARA DISCUSSÃO}

Para que o debate flua, propomos que algumas questões sejam levantadas para iniciar discussão.

1) Que tipo de amostragem você recomendaria, considerando os objetivos do projeto de pesquisa e as dificuldades em definir o universo e o plano amostral de empresas localizadas em Barueri?

2) Considerando as seguintes fontes de dados: respondentes, situações análogas, experimentação e dados secundários, que tipos de fontes de dados são adequados para o objetivo a que o projeto Conhecendo Tamboré se propõe?

3) Considerando as seguintes formas de abordagem: observação pessoal, observação mecânica, auditoria, análise de conteúdo, análise de traço, entrevista pessoal, entrevista telefônica e entrevista postal, que formas você utilizaria no projeto de pesquisa em questão?

4) Quais as limitações e erros trazidos aos dados, que essas fontes e abordagens podem ocasionar? Como contornar estes problemas?

5) A que erros alheios à amostragem esta pesquisa está exposta?

\section{Análise do Caso}

Pode-se começar a discussão abordando a constante necessidade de obter dados sobre o ambiente no qual uma organização qualquer esteja inserida. Isto é válido para atividades de planejamento empresarial em geral, seja marketing, gestão de pessoas ou para estratégias de negócio ou corporativas. Conhecer o ambiente é a primeira grande atividade de um trabalho de planejamento estratégico.

Deve-se destacar quão difícil é obter dados primários, vide as tentativas das pesquisadoras. Mesmo bases de dados públicas, como a do município de Barueri, requerem análise antes de serem consideradas como recurso disponível para um processo decisório. Há que pensar nos limites e nos erros em que se pode incorrer. Portanto, cabe a mesma atenção tanto para definir quais informações são relevantes quanto para estabelecer como serão conseguidos os dados; ambos são momentos cruciais para obtenção de dados íntegros, válidos e confiáveis para um processo decisório. Em vista disto, vamos analisar as estratégias adotadas no estudo e as relações com a teoria.

As pesquisadoras planejaram, inicialmente, utilizar como fonte de dados para a pesquisa, dados secundários provenientes do site www.barueri.sp.gov.br, assim como informações coletadas com os gestores das empresas da região (respondentes). Segundo Kinnear e Taylor (1996), são quatro as fontes básicas de dados: respondentes, situações análogas, experimentação e dados secundários. De acordo com o exposto, você concorda com a estratégia adotada ou pode sugerir outra(s) fonte(s) de dados?

A técnica de coleta de dados e forma de abordagem adotada foi levantamento por meio de entrevista postal. Segundo Malhotra (2001) e Aaker, Kumar e Day (1995), existem duas formas de coleta de dados: levantamento e observação. Os autores afirmam que as formas de abordagem para a técnica de observação são: observação pessoal, observação mecânica, auditagem, análise de conteúdo e análise de traços. Já as formas de abordagem para a técnica de levantamento são: entrevista pessoal, entrevista telefônica e entrevista postal. Considerando essas informações, que técnica de coleta de dados e forma de abordagem você utilizaria? E ainda, considerando que é possível combinar as formas de abordagem, conforme sugere Aaker et al. (1995) na figura 2, que combinação de abordagem você utilizaria para o caso proposto? 
Quanto ao tipo de amostragem, as pesquisadoras propuseram, inicialmente, amostragem probabilística estratificada (estratificada por setor econômico); no final da pesquisa, já estavam cogitando a possibilidade de utilizar amostragem não-probabilística por acessibilidade. Sabemos que existem dois grandes grupos de amostragem: a amostragem probabilística, que permite generalizações para a população; e a amostragem não-probabilística, que não garante a representatividade da população. Sabemos ainda que os tipos de amostragem probabilística mais usuais são: aleatória simples, estratificada, sistemática e conglomerado. Já os tipos de amostragem não-probabilística são: acessibilidade, julgamento e cotas. Considerando todas essas possibilidades de tipos de amostragem, que tipos de amostragem você utilizaria?

Durante o desenrolar da pesquisa, as pesquisadoras encontraram algumas dificuldades na coleta de dados, que poderiam ser potenciais fontes de erro. Sabemos também que o erro total de uma pesquisa é composto por erros de amostragem e por erros alheios à amostragem, segundo Pérez (1999), conforme mostra a figura 3 . Utilizando como base a figura 3 , a que erros alheios à amostragem a pesquisa estava exposta?

Como vimos, é de fundamental importância estabelecer, com base nos objetivos do projeto, quais serão as formas para a coleta das informações, quais os critérios de amostragem e quais são os possíveis limites e erros em que se pode incorrer, considerando o que cada forma de coleta e análise implica, lembrando que uma das principais competências do gestor contemporâneo é a capacidade de tomar decisões rápidas, porém com pertinência.

\section{Conteúdo Teórico Relevante}

\section{Fontes Básicas de Dados de Pesquisa}

Para Kinnear e Taylor (1996), há quatro fontes básicas de dados de pesquisa: respondentes, situações análogas, experimentação e dados secundários. Essas fontes são acessadas por meio de técnicas de coleta, que podem ser de duas naturezas: observação e levantamento. Cada uma dessas técnicas utiliza abordagens distintas. Na observação, segundo Malhotra (2001), podemos utilizar as seguintes abordagens: observação pessoal, observação mecânica, auditoria, análise de conteúdo e análise de traço. No levantamento, segundo Aaker et al. (1995), há três abordagens básicas: entrevista pessoal, entrevista telefônica e entrevista postal. (Figura 1)

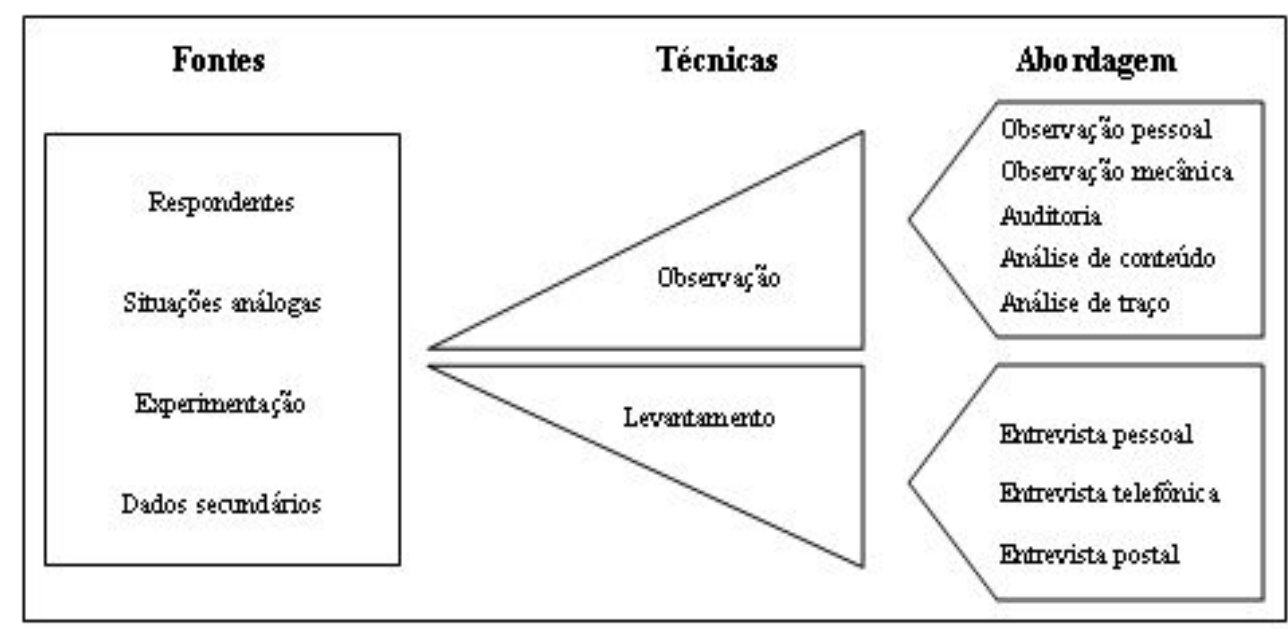

Figura 1. Dados: Fontes, Técnicas de Coleta e Formas de Abordagem

Essas classificações de fontes de dados, técnicas de coleta e formas de abordagem estão apresentadas a seguir. 


\section{Fontes de Dados}

As quatro fontes de dados relacionadas por Kinnear e Taylor (1996) constituem famílias amplas. Segundo esses autores,

Os respondentes são as maiores fontes de dados. Há dois métodos principais de se obter dados dos respondentes: comunicação e observação. Comunicação requer que o respondente tenha um papel ativo de prover informação, enquanto que a observação requer o registro do comportamento passivo do respondente.

O exame de situações análogas é forma lógica de estudar uma situação de decisão e inclui os estudos de caso e simulações.

A experimentação é fonte relativamente nova de dados. Os dados de um experimento são organizados de tal forma que podem ser testadas premissas em relações de causa e efeito. Um experimento é realizado quando uma ou mais variáveis independentes são premeditadamente controladas ou manipuladas, e seus efeitos na(s) variável(eis) dependente(s) são medidos.

. Dados secundários são aqueles já publicados e podem ser classificados como originários de fontes internas ou externas.

\section{Técnicas de Coleta}

Para Malhotra (2001, p. 193), a "observação envolve o registro sistemático de padrões de comportamento das pessoas, objetos e eventos, a fim de obter informações sobre o fenômeno de interesse. O observador não interroga as pessoas que estão sendo observadas, nem se comunica com elas".

Já o levantamento, segundo Aaker et al. (1995), é a principal escolha dos pesquisadores para a coleta de dados primários. Sua principal vantagem é a capacidade de coletar uma grande quantidade de dados sobre um respondente individual, de uma só vez. Para vários tipos de dados, o levantamento é o único modo de coleta. A segunda vantagem dessa técnica é a versatilidade, sendo adaptável para pesquisas tanto do tipo descritivo quanto causal.

\section{Formas de Abordagem}

Na visão de Malhotra (2001), a técnica da observação pode classificar-se, segundo sua forma de abordagem, em observação pessoal, observação mecânica, auditagem, análise de conteúdo e análise de traços. De modo resumido, o autor apresenta essas formas como segue.

Observação pessoal é a estratégia de pesquisa de observação em que os observadores humanos registram o fenômeno em análise tal como ele ocorre.

Observação mecânica é a estratégia de pesquisa observacional em que dispositivos mecânicos, e não observadores humanos, registram o fenômeno que está sendo observado.

Auditoria é a forma de abordagem na qual o pesquisador coleta os dados examinando os registros físicos ou fazendo análise do inventário.

Análise de conteúdo é a descrição objetiva, sistemática e quantitativa do conteúdo efetivo de uma comunicação.

Análise de traço é a abordagem em que a coleta de dados está baseada em traços físicos, ou evidências, de um comportamento passado. 
Segundo Aaker et al. (1995), as três modalidades de abordagem relacionadas aos levantamentos podem ser sintetizadas da seguinte forma.

Entrevista pessoal é a abordagem em que o processo é caracterizado pela interação de quatro entidades: pesquisador, entrevistador, entrevistado e ambiente de entrevista. Coletivamente essas características influem no processo de entrevista e, em última análise, na entrevista em si. Durante a entrevista pessoal, entrevistador e entrevistado interagem e simultaneamente influenciam um ao outro.

Entrevista telefônica é uma abordagem cujo processo é, geralmente, bastante similar à entrevista pessoal. Há somente alguns aspectos únicos da entrevista telefônica, tais como a seleção de números telefônicos, a resposta a chamadas, a apresentação, o momento da chamada e os relatórios de chamada que exigem técnicas específicas.

- Entrevista postal pode ser realizada tanto via correio tradicional, quanto por fax ou correio eletrônico. Nesta abordagem, tradicionalmente têm sido enviados questionários a potenciais participantes do estudo, que os completam e devolvem. Ao contrário da entrevista pessoal e telefônica, a entrevista postal requer ao menos alguma identificação do indivíduo participante da amostra antes que a coleta de dados se inicie, uma vez que é necessário um endereço - físico ou eletrônico - para o questionário ser postado.

Uma vez que cada uma das abordagens tem características próprias, algumas vezes é útil combinálas para alcançar o melhor de cada uma delas e minimizar suas limitações. Algumas combinações ou sequências factíveis foram relacionadas por Aaker et al. (1995) e estão ilustradas na Figura 2.

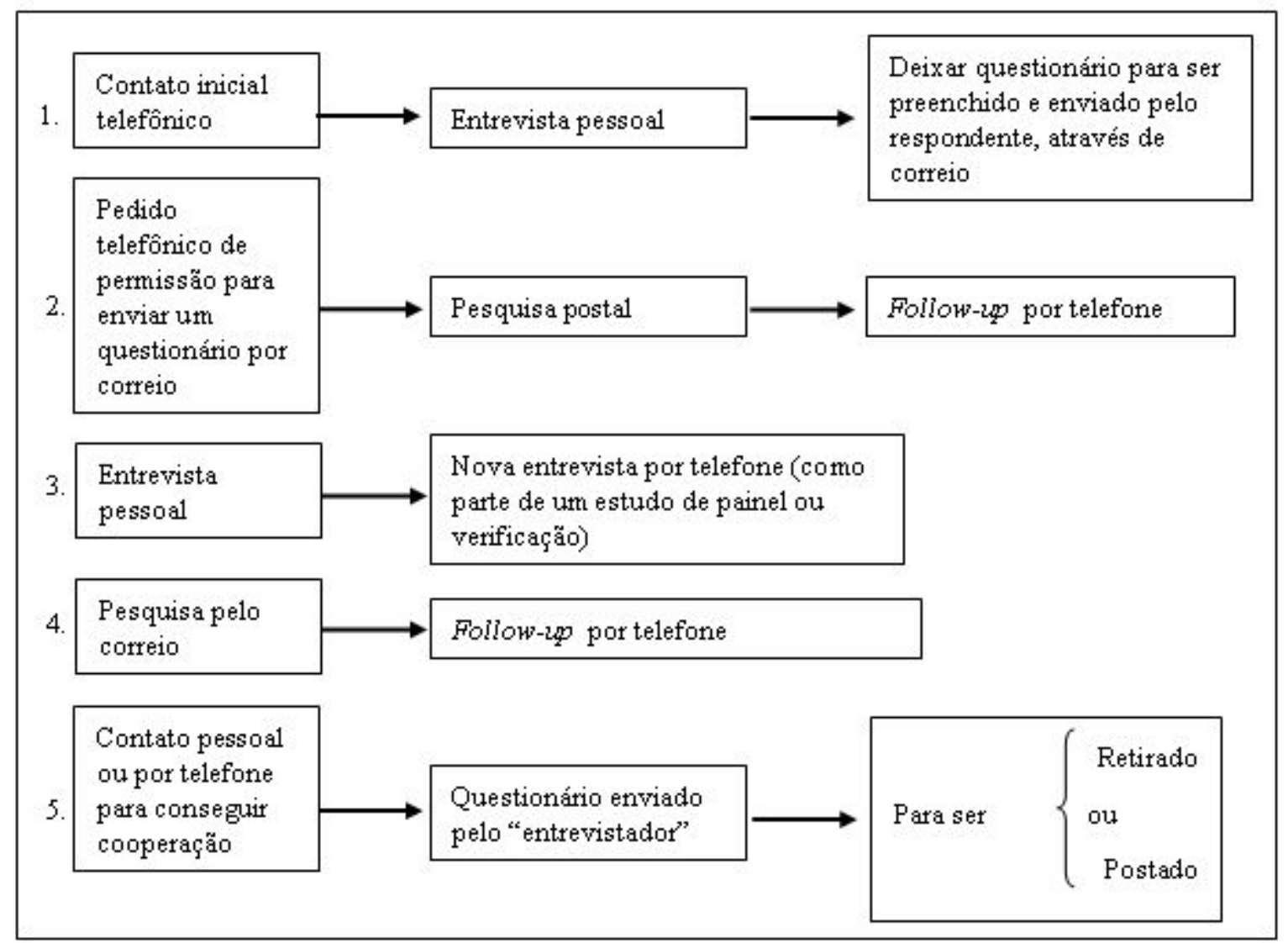

Figura 2. Combinações ou Sequências de Abordagens

Fonte: Aaker et al. (1995, como citado em Guimarães, R. T. (2005). Avaliação de marca das instituições de ensino superior no segmento de mestrado e doutorado em administração: uma abordagem multivariada. Tese de doutorado, Universidade de São Paulo, São Paulo, Brasil, p. 120). 


\section{Classificação dos Tipos de Amostragem}

Nas pesquisas, em geral, são utilizados diversos tipos de amostragens, que são classificadas em dois grandes grupos: amostragens probabilísticas e não-probabilísticas. A amostragem probabilística exige que cada elemento da população possua determinada probabilidade de ser selecionado, e os elementos que irão compor a amostra são sorteados aleatoriamente. Ao utilizarmos um procedimento de amostragem probabilística, é possível a generalizar os resultados da pesquisa para a população. Os tipos mais comuns de amostragem probabilística são aleatória simples, estratificada, sistemática e por conglomerado. Já na amostragem não probabilística, há escolha deliberada dos elementos da amostra e não é possível generalizar os resultados das pesquisas para a população, pois as amostras nãoprobabilísticas não garantem a representatividade da população. Os procedimentos da amostragem não-probabilística mais usuais são por acessibilidade, por julgamento e por quotas. Segundo Osuna (1991), os procedimentos não-probabilísticos são muito mais críticos em relação à validade de seus resultados; todavia apresentam algumas vantagens, sobretudo no que se refere ao custo e ao tempo despendido.

Segundo Pérez (1999), quando executamos uma pesquisa, devemos ter em mente que estamos sempre sujeitos a erros. Esses erros ocorrem por diversas causas e podem ser classificados em erros de amostragem (ou erros aleatórios) e erros alheios à amostragem (ou erros sistemáticos). Como exemplo de erros de amostragem, podemos citar o erro originário da variabilidade dos valores obtidos no processo de amostragem; como exemplo de erros alheios à amostragem, há os erros produzidos por métodos tendenciosos de medição. (Figura 3)

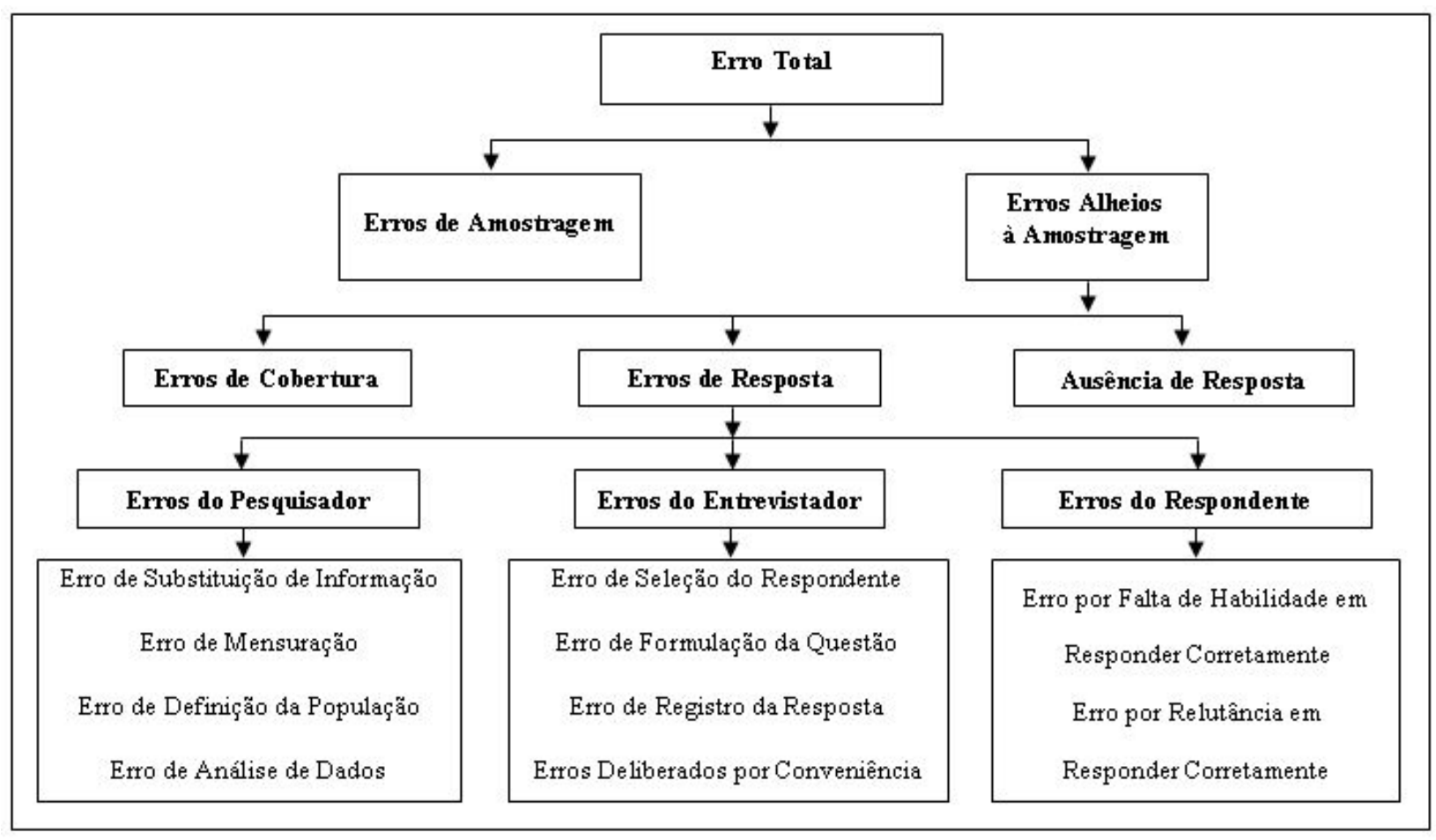

Figura 3. Erro Total

Fonte: Pérez (1999, como citado em Torres, R. R. (2000). Estudo sobre os planos amostrais das dissertações e teses em Administração da Faculdade de Economia, Administração e Contabilidade da Universidade de São Paulo e da Escola de Administração da Universidade Federal do Rio Grande do Sul: uma contribuição crítica. Dissertação de mestrado, Universidade de São Paulo, São Paulo, Brasil, p. 148).

Podem ocorrer erros nos resultados, em uma amostra particular, segundo Pérez (1999), causados pelos respondentes, entrevistadores, codificadores ou outros sujeitos envolvidos com a pesquisa, assim como é possível que o motivo do erro compreenda mais de um destes. O entrevistado, por exemplo, pode não compreender a pergunta, não conhecer as respostas ou ser influenciado pelo entrevistador. 
Os erros de amostragem e os erros alheios à amostragem têm, em geral, distintas fontes, efeitos e métodos de medida. A redução dos erros de amostragem pode ser assegurada com o aumento do tamanho da amostra; entretanto, para reduzir os erros alheios à amostragem, é preciso algo mais, como, por exemplo, uma supervisão ou um programa de controle. Para Malhotra (2001), é importante salientar que há muitas fontes de erro e que, em pesquisa, o pesquisador deve tentar minimizar o erro total e não somente uma única fonte de erro em particular.

\section{Desdobramentos do Projeto de Pesquisa}

Para fins de esclarecimento, cabe fazer saber aos docentes que utilizarem este Caso de Ensino que as pesquisadoras lançaram mão de várias tentativas para estabelecer amostragem probabilística, tal qual haviam proposto no projeto de pesquisa aprovado pelo MackPesquisa. Vistas todas as dificuldades para conseguir dados sobre empresas que estivessem de fato em Barueri, as docentes fizeram o seguinte.

Tendo em mãos o banco de dados elaborado pela Prefeitura de Barueri, ambulantes, farmácias, açougues, bancas de jornais, cabeleireiros, entre outros setores, foram imediatamente excluídos, considerando improvável encontrar ali profissionais relacionados a uma instituição de ensino superior de administração de empresas. Analogamente, excluíram microempresas [ME], retirando das listagens todos aqueles registros que contivessem ME na razão social. Com estas determinações, chegaram a um universo de 2973 nomes, aproximadamente; houve sensível diminuição em relação aos 19.000 iniciais, mas ainda havia um universo muito grande e, pior ainda, desconhecido.

Saíram pelo município de automóvel e tomaram nota do nome das empresas ao passar por elas, nas vias públicas. Este método é perfeito para garantir que o contato seria mesmo feito com empresas que, de fato, estão localizadas em Barueri. Porém ainda restava o trabalho de contato e de convencimento à participação da organização na pesquisa, além de ser método caro, dispendioso e que exige muito tempo.

Obter do IBGE uma lista de empresas selecionadas via censo empresarial. Após obter algumas respostas a questionários enviados eletronicamente, as pesquisadoras concluíram que havia uma relação positiva entre tamanho da empresa, em termos de quantidade de funcionários e possibilidades de parceria, com uma Instituição Superior de Ensino. Empresas com mais funcionários têm, em geral, mais chance de se interessar por aproximação com organizações que proporcionem formação e treinamento. As docentes entraram, então, em contato com o IBGE para que disponibilizasse os nomes e o contato de empresas com mais de 100 funcionários trabalhando em Barueri. Com esta tentativa, foi possível conseguir uma lista com 214 nomes de empresas localizadas no município.

Após todas estas tentativas, o trabalho de levantamento resultou em 115 registros, dos quais 89 foram considerados válidos. A amostra, inicialmente definida como probabilística estratificada, precisou ser redefinida, tornando-se uma amostra não-probabilística por acessibilidade. Com estas empresas, foram realizadas análises exploratórias, certos das limitações que estes resultados podem ter em função das dificuldades para definir o próprio universo de pesquisa.

\section{NOTAS}

\footnotetext{
${ }^{1}$ Fundo Mackenzie de Pesquisa, abreviadamente MackPesquisa, foi criado em 1997 e é regulado por regimento próprio, aprovado em 28 de novembro de 1998 pelo Conselho Deliberativo do Instituto Presbiteriano Mackenzie. O MackPesquisa tem como objetivo básico incentivar a prática da investigação, pura ou aplicada, financiando projetos de pesquisa de interesse institucional, de acordo com a viabilidade econômica do Fundo e da relevância científica do projeto. (Fonte: http://www.mackenzie.br/mackpesquisa).

${ }^{2}$ Tal entendimento sobre o conceito de projeto pedagógico está contido em obras como Masetto, M. T. (2003). Competência pedagógica do professor universitário. São Paulo: Summus e Zabalza, M. A. (2004). O ensino universitário: seu cenário e seus protagonistas. Porto Alegre: Artmed.
} 


\section{REFERÊNCIAS BIBLIOGRÁFICAS}

Aaker, D. A., Kumar, V., \& Day, G. S. (1995). Marketing research (5 ${ }^{\text {th }}$ ed.). New York: John Wiley \& Sons.

Guimarães, R. T. (2005). Avaliação de marca das instituições de ensino superior no segmento de mestrado e doutorado em administração: uma abordagem multivariada. Tese de doutorado, Universidade de São Paulo, São Paulo, Brasil.

Kinnear, T. C., \& Taylor, J. R. (1996). Marketing research: an applied approach (5 ${ }^{\text {th }}$ ed.). New York: McGraw-Hill.

Malhotra, N. K. (2001). Pesquisa de marketing: uma orientação aplicada. Porto Alegre: Bookman.

Osuna, J. R. (1991). Métodos de muestreo. España: CIS.

Pérez, C. (1999). Técnicas de muestreo estadístico: teoría, práctica y aplicaciones informáticas. Madrid: RA-MA.

Torres, R. R. (2000). Estudo sobre os planos amostrais das dissertações e teses em Administração da Faculdade de Economia, Administração e Contabilidade da Universidade de São Paulo e da Escola de Administração da Universidade Federal do Rio Grande do Sul: uma contribuição crítica. Dissertação de mestrado, Universidade de São Paulo, São Paulo, Brasil. 